\title{
Irreversibility, Option Demand and Environmental Preservation
}

\author{
Etienne Bienvenu Akono \\ Faculty of Economics and Applied Management \\ University of Douala, P.O. Box 4032 Douala, Cameroon \\ Tel: 237-33-40-3833Ｅ-mail: akonosong@yahoo.fr
}

Received: May 13, 2013 Accepted: May 30, 2013

doi:10.5296/emsd.v2i2.3680 URL: http://dx.doi.org/10.5296/emsd.v2i2.3680

\begin{abstract}
The purpose of this article is to analyze the government's choice between preservation and irreversible development when there is a willingness to pay for retaining the option to use the environmental site. Extending the model used by Mäler \& Fisher, I show that in the context of uncertainty about future benefits, the government would choose to preserve the land when there is an option demand to refrain from using it.
\end{abstract}

Keywords: irreversibility; uncertainty; option demand; environmental preservation

\section{Introduction}

The purpose of this paper is to analyze the government's choice on whether to preserve or to construct a hydroelectric dam when there is a willingness to pay for retaining the option to use the environmental area. Extending the model used by Mäler \& Fisher (2005) to explore the problem of choosing whether to preserve or to develop a tract of land, I show that in the context of uncertainty about future benefits, the government would choose to preserve the land when there is an option demand to refrain from using the environmental site.

Cameroon's government has launched in June 2012, for a value of US \$ 840 million, the construction of a hydroelectric dam in Memve'ele waterfalls in order to boost the electricity supply. Memvele'ele waterfalls are one of the richest biodiversity areas of the Campo-Ma'an landscape. The Campo-Ma'an is located in the southwestern corner of Cameroon bordering to the west by the Atlantic Ocean. The Campo-Ma'an features a National park containing 80 animal mammals such as forest elephants, leopards and gorillas; 302 bird species; 122 reptile species and 250 fish species. The Campo-Ma'an also contains a coastline of $65 \mathrm{~km}$ with attractive beaches, diverse ethnic groups with different cultural heritage and archaeological sites. 


\section{Mll Macrothink}

The particularity of Memve'ele waterfalls is that they are very close to the biologically part of the Campo-Ma'an National Park. The proximity of the Memve'ele hydroelectric dam with the park is then a great concern. A simulation of the zone of impact of the Memve'ele dam within a radius of $25 \mathrm{~km}$ shows that the park's richest part in terms of wildlife will be seriously affected by the dam construction (World Wildlife Fund [WWF], 2008).

When the existence of a grand scenic wonder or a unique and fragile ecosystem, such as Campo-Ma'an National Park is involved, its preservation and continued availability are significant part of the real income of many individuals (Krutilla, 1967). In fact, people anticipate visiting the park at sometime in the future although they never will visit it. If these people are rational, they will be willing to pay for retaining the option to visit the park in the future (Weisbrod, 1964). A question can therefore arise: should the Campo-Ma'an National Park be preserved in its natural state for wilderness recreation or further developed as hydroelectric facility when there is an option demand to refrain the use of the park for that purpose?

Fisher, Krutilla and Ciccheti (1972), Arrow and Fisher (1974), Henry (1974a, 1974b), Fisher and Hanemann (1986), Albers. Fisher and Hanemann (1996) and Mäler and Fisher(2005) study a similar question of whether to preserve or develop a tract of land. In particular, Fisher et al. (1972), focusing on the hydroelectric dam project along the Hells Canyon of the Snake River, show that it will be not optimal to undertake even the most profitable project there, rather the area is likely to yield greater benefits if left in its natural state. The uncertainty surrounding the consequences of an irreversible action might then militate for refraining the hydroelectric dam construction. Arrow and Fisher (1974) approve implicitly this idea while exploring the implications of uncertainty on estimates of environmental costs of some activities. They show that the existence of uncertainty will lead to a reduction in net benefits form an activity with environmental costs. In the same vein, Mäler and Fisher (2005) analyze actions that may have irreversible effects but where the decision-maker can improve her information about the true preferences. They show that current development is less likely with the prospect that information about uncertain environmental values will be forthcoming in the future.

The literature considers then uncertainty about future benefits as a key factor influencing the choice of a decision-maker between preservation and irreversible development of an environmental site. Of course, the environmental field is permeated by uncertainty, and it is interesting and far from trivial to analyze the effect of that uncertainty. However, the choice of a decision-maker on whether to preserve or to develop an environmental area could also be influenced by an option demand i.e. a willingness to pay for retaining an option to use the environmental site. To my knowledge, the option demand has not yet been formally studied by the literature as a factor determining the choice of a decision-maker on whether to develop or to preserve an estate of land. This paper attempts to fulfill this lack.

\section{Model}

This framework is inspired from the model used by Mäler \& Fisher (2005) to study the problem of whether to preserve or to develop a tract of estate. I extend it by using the option 
demand as a factor determining the choice of the government between preservation and irreversible development.

Let consider a government facing an electricity supply shortage. To boost the electricity production the government plans to set up an irreversible development by constructing an electric dam in a waterfalls area rich in biodiversity. Let assume that there are economic agents anticipating to visit and enjoy the beauty of waterfalls and its rich biodiversity. Let suppose that those agents are rational and so they are willing to pay to preserve this environmental area. This assumption means that there is an option demand for retaining the option to use the waterfalls to construct the hydroelectric dam. Let assume that the government is rational and so its choice, on whether to preserve or develop the waterfalls site, could be influenced by the option demand. To simplify, let assume that the government is able to quantify this option demand and will decide to preserve the land for recreation wilderness if the option demand exists. I further assume that the existence of the option demand is equivalent to state that the option demand is positive. The option demand is automatically satisfied when the environmental site exists. It will then pay every potential user to mask his preferences in order to minimize his private cost. Taking to account this pure public good nature of the option demand, let assume that when the option demand is positive this ensures its availability and its sufficiency to offset the benefits stemming from the construction of the dam.

Let denote $e_{i}$, the electricity volume produced by the dam at period $i$. To simplify let suppose that $e_{i}=0$ when the dam is not constructed at period $i$ while $e_{i}=1$ when the dam is constructed at that period. Let further suppose that the electricity dam is constructed only in one period and cannot be constructed during many periods. This means implicitly that if the dam is not constructed at period one, it will be constructed in the future. Let consider for simplicity, period one as the present and period two as the future.

Let denote the government's benefit from the construction of the hydroelectric dam at period one net of the environment cost by $B_{1}\left(e_{1}\right)$, where $e_{1}$ can be zero or one. The present value of the government's benefit from the construction of the electric dam at period two is denoted by $B_{2}\left(e_{1}+e_{2}, \theta\right)$ where $e_{2}$ can be zero or one and $\theta$ is a random variable. Note that, if $e_{1}=1$ then $e_{2}=0$.

Let denote $\hat{V}\left(e_{1}\right)$, the government's expected benefits over both periods when uncertainty about future benefits can be resolved. At we can see, that expected benefits depend on the government's choice to construct or to not construct the hydroelectric dam at period one ( $e_{1}=0$ or $e_{1}=1$ ) given that $e_{2}$ is chosen to maximize benefits at period two. 
For $e_{1}=0, \hat{V}(0)=B_{1}(0)+E\left[\max _{e_{2}}\left\{B_{2}(0, \theta), B_{2}(1, \theta)\right\}\right]$

For $e_{1}=1, \quad \hat{V}(1)=B_{1}(1)+E\left[B_{2}(1, \theta)\right]$

Note that, if the government decides to construct the dam at period one, there will be an electric dam over both periods $\left(e_{1}=1 \Rightarrow e_{1}+e_{2}=1\right)$.

To get the government's choice at period one, $\hat{e}_{1}$, compare:

$\hat{V}(0)-\hat{V}(1)=B_{1}(0)-B_{1}(1)+E\left[\max _{e_{2}}\left\{B_{2}(0, \theta), B_{2}(1, \theta)\right\}\right]-E\left[B_{2}(1, \theta)\right]$

The government chooses then $\quad \hat{e}_{1}=\left\{\begin{array}{l}0, \text { if }, \hat{V}(0)-\hat{V}(1) \geq 0 \\ 1, \text { if }, \hat{V}(0)-\hat{V}(1) \prec 0\end{array}\right.$

Let now suppose that the uncertainty about the government's benefits cannot be resolved. Let denote, for this case, by $V^{*}\left(e_{1}\right)$ the government's expected benefits over both periods.

$$
\begin{array}{ll}
\text { For } e_{1}=0, & V^{*}(0)=B_{1}(0)+\max _{e_{2}}\left\{E\left[B_{2}(0, \theta), B_{2}(1, \theta)\right]\right\} \\
\text { For } e_{1}=1, & V^{*}(1)=B_{1}(1)+E\left[B_{2}(1, \theta)\right]
\end{array}
$$

As mentioned above, there will be always an electric dam over both periods. To get the government's choice at period one compare:

$V^{*}(0)-V^{*}(1)=B_{1}(0)-B_{1}(1)+\max _{e_{2}}\left\{E\left[B_{2}(0, \theta), B_{2}(1, \theta)\right]\right\}-E\left[B_{2}(1, \theta)\right]$

The government chooses then $\quad e_{1}^{*}=\left\{\begin{array}{l}0, \text { if }, V^{*}(0)-V^{*}(1) \geq 0 \\ 1, \text { if }, V^{*}(0)-V^{*}(1) \prec 0\end{array}\right.$

\section{Result and Discussion}

Bear in mind that the government's choice to preserve or develop the environmental site when there is an option demand depends on the sign of that option demand as assumed in the previous section. Let then firstly formalize the option demand. 
Referring to the work of Mäler \& Fisher (2005) and from equations (3) and (7), the option demand is formally determined by the relation $[\hat{V}(0)-\hat{V}(1)]-\left[V^{*}(0)-V^{*}(1)\right]$. Since $\hat{V}(1)=V^{*}(1)$, the option demand is then determined by the equation $\hat{V}(0)-V^{*}(0)$.

Replacing $\hat{V}(0)$ and $V^{*}(0)$ by their respective relations, we get:

$$
\hat{V}(0)-V^{*}(0)=E\left[\max _{e_{2}}\left\{B_{2}(0, \theta), B_{2}(1, \theta)\right\}\right]-\max _{e_{2}}\left\{E\left[B_{2}(0, \theta), B_{2}(1, \theta)\right]\right\}
$$

From the convexity of the maximum function and Jensen's inequality, the expected value of a convex function is greater or equal to the convex function of the expected value of the random variable. Referring to that theorem, it is straightforward to see that $\hat{V}(0)-V^{*}(0) \geq 0$, meaning that the option demand is positive. Since the government is assumed to be rational and its choice on whether to preserve or to construct the hydroelectric dam depends on the sign of the option demand, the government would then choose to preserve the waterfalls area rather than constructing a hydroelectric dam on it because the option demand to retain the use of the land is positive. In other words, the government would refrain to construct a hydroelectric dam on the waterfalls area when there are people willing to pay to preserve that environmental site.

\section{Conclusion}

This article showed that the government would choose to preserve the waterfalls area, instead of constructing on it a hydroelectric dam which is irreversible, when there are people willing to pay for retaining the option to use the waterfalls as an electric facility. To obtain this result, I extend the two-period model used by Mäler \& Fisher (2005) by using the option demand as a factor determining the choice of the government on whether to preserve or to develop a tract of land.

This study is still admittedly incomplete. The paper has not taken to account the features of the option demand as public good to analyze the government's choice between preservation and development. An interesting task will be to examine it.

\section{References}

Albers, H. J., Fisher, A. C., \& Hanemann, W. M. (1996). Valuation and management of tropical forests: Implication of uncertainty and irreversibility. Environmental and Resource Economics, 8, 39-61.

Arrow, K. J., \& Fisher, A. C. (1974). Environmental Preservation, Uncertainty and Irreversibility. The Quarterly Journal of Economics, 88(2), 312-319. http://dx.doi.org/10.2307/1883074 . 


\section{Macrothink}

Environmental Management and Sustainable Development

ISSN 2164-7682

2013, Vol. 2, No. 2

Fisher, A.C., \& Hanemann, W. M. (1986). Option value and the extinction of species. In V.K. Smith (Ed.), Advances in Applied Microeconomics (pp. 169-190). Greenwich, CT: JAI Press.

Fisher, A. C., Krutilla, J. V., \& Ciccheti, C. J. (1972). The Economics of Environmental Preservation: A Theoretical and Empirical Analysis. The American Economic Review, 62(4), 605-619.

Henry, C. (1974a). Investment decisions under uncertainty: The irreversibility effect, in Review of Economic Studies, Symposium on the Economics of Exhaustible Resources.

Henry, C. (1974b). Option values in the economics of irreplaceable assets, in Review of Economic Studies, Symposium on the Economics of Exhaustible Resources.

Krutilla, J. V. (1967). Conservation Reconsidered. The American Economic Review, 57(4), 777-786.

Mäler, K.-G., \& Fisher, A. C. (2005). Environment, Uncertainty, and Option Values. In K.-G. Mäler, \& J. R. Vincent ( Eds.), Handbook of Environmental Economics (pp.571-620), Vol. 2. Elsevier B. V.

Weisbrod, B. A. (1964). Collective-Consumption Services of Individual-Consumption Goods. The Quarterly Journal of Economics, 78 (3), 471-477. http://dx.doi.org/10.2307/1879478

World Wildlife Fund. (2008). Elephants and African Great Apes, Campo-Ma'an: A Census shows a stabilization of key Wildlife Species (No 003). Campo Ma'an, Kudu-Zombo Program: Author. Retrieved from http://awsassets.panda.org/downloads/kz_3_anglais_final.pdf.

\section{Copyright Disclaimer}

Copyright reserved by the author(s).

This article is an open-access article distributed under the terms and conditions of the Creative Commons Attribution license (http://creativecommons.org/licenses/by/3.0/). 